\title{
Investigating the contribution of geometrical parameters and immersion time on fracture toughness of jute fabric composites using statistical techniques
}

\author{
G. B. Manjunatha \\ Department of mechanical engineering, G M Institute of technology, Karnataka, India, \\ Manjugb4444@gmail.com, bttps://orcid.org/0000-0001-8942-8887 \\ K. N. Bharath \\ Department of mechanical engineering, G M Institute of technology, Karnataka, India, \\ kn.bharath@gmail.com, bttps://orcid.org/0000-0003-1004-099X
}

ABSTRACT. The aim of this work is to evaluate the failure analysis of jute fabric reinforced composite using statistical technique for marine applications. A fracture mechanics approach is proposed to determine the failure load and fracture toughness of the composite. Jute fiber reinforced epoxy composites were fabricated by hand lay-up technique. The polymer composite is intended for marine applications as an alternative material, mainly in high moisture environments. Thus an investigation was conducted to evaluate the fracture mechanic parameter by immersing composite specimens in sea water. The statistical method of Taguchi was used for experimental design. Edge Notched Tension (ENT) and Single Edge Notched Bend (SENB) test were conducted according to the ASTM E1922 and ASTM D5045 respectively. Main effect graphs are obtained to study the effect of a/w (Crack length to width ratio), thickness and immersion time of composite on fracture mechanics parameters. The approach of calculating the percentage of contribution of control factors was established using by analysis of variance (ANOVA). The influence of fracture parameters of control factors can be analysed by using 3-D response surface graph (RSM). The Validation of experimental results for fracture parameters agreed well with the predicted values.

KEYWORDS. Polymer composites; Natural fiber; Fracture toughness; Taguchi; ANOVA; RSM.

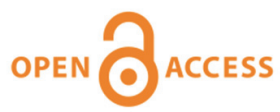

Citation: Manjunatha, G. B., Bharath, K. N., Investigating the contribution of geometrical parameters and immersion time on fracture toughness of jute fabric composites using statistical techniques, Frattura ed Integrità Strutturale, 46 (2018) 14-24.

Received: 07.03 .2018

Accepted: 07.04.2018

Published: 01.10 .2018

Copyright: (C) 2018 This is an open access article under the terms of the CC-BY 4.0, which permits unrestricted use, distribution, and reproduction in any medium, provided the original author and source are credited. 


\section{INTRODUCTION}

$\mathrm{E}$ merging environmental awareness and social concern, the unmanageable consumption of petroleum, and new system demands for eco- friendly materials with economic. Fiber-reinforced composite materials have some advantages such as high stiffness, relatively good resistance to environmental actions, recyclable, fatigue and failure resistance, etc. [1]. The natural fibers are a large amount of moisture absorbed. The absorption of water in a polymeric matrix is a volumetric diffusion process which follows the Fick's law [2]. It's an important issue nature life when composite materials are subjected to both mechanical loadings and exposed to severe environmental conditions [3]. In recent developments, the laminated polymer matrix composite materials are being extensively used in extreme environments. Correspondingly needs to be characterizing the fracture toughness over environmental conditions. This behaviour has been interrelated to the effect of moisture on matrix ductility, an amount of matrix deformation and the size of the plastic zone around the crack tip that occurs during fracture [4]. For fiber-reinforced composite materials, the interlaminar and/or intralaminar interface will have a great effect on their fracture mechanisms. The interface is probably the weakest part of a fracture process. Hence, the enhancement of interface behaviour is even more important [5]. The advance of fracture mechanics tests methods for the determination of delamination resistance or fracture toughness of fiber-reinforced polymer matrix composites is an active area of research [6]. Many machine elements have failed in the form of holes, notches, or cracks that are very significant factors influencing stress distributions in the structures. In such cases, stress cannot be defined as a strength parameter. Mechanical systems are designed by using the fracture mechanics' parameter as fracture toughness and can be used during the determination of the material strength against crack growth under external loads [7]. The increased use of polymer composites also requires the understanding of the fracture behaviour. Evaluation of damage and prediction of residual strength and fracture toughness is critical because the deboned can grow in an unstable manner and finally leads to catastrophic failure [8]. Fiber-reinforced composites used structural materials. Since these structures are to be used under some environmental conditions. It's necessary for understanding the environmental effects on the fracture toughness and deformation behaviour to prevent damage to the structure. Among the many different kinds of environmental effect, the hydrothermal effect is one of the most important issues for polymeric composites [9].

Taguchi methods are statistical methods developed by Grenichi Taguchi to improve high-quality products at a low-cost [10]. By using the Taguchi techniques, industries are able to greatly reduce cycle time for both design and production. The objective of this technique is to optimize the settings of the process parameter values for improving performance characteristics. The design of parameters is the key step in the Taguchi method [11]. Design of Experiment (DOE) is one of the extensively used methods for experimental study. DOE is a statistical approach in which a mathematical model is established through experimental results. The trial data were developed in a pattern of L9 Orthogonal Array (OA) So possible output can be predicted based on the input parameters of the experimentation. Results can be analysed by using analysis techniques such as ANOVA and linear regression [12]. Experimental results are shown by plotting response surface methodology (RSM) graph.

\section{MATERIALS AND EXPERIMENTAL METHODS}

\section{Specimen Preparation}

7 he specimens used in the present study were fabricated using a hand lay-up technique. Main materials are jute fiber and epoxy polymer. The $40 \%$ of volume fraction as matrix material used is a medium viscosity epoxy resin (LAPOX L-12) and a room temperature curing hardener (K-6). It provides excellent resistance to alkalis and good adhesive properties [13]. Jute fiber of $60 \%$ used as reinforcement by volume fraction in this composite material. The specimens were dipped in seawater about 7, 14, 21 days.

\section{Fracture Testing}

The experiment was conducted on a computerized universal testing machine (UTM). For ENT, loading fixtures are used on the specimen to maintain a tensile load on the crack tip is uniaxial. The load was applied eccentrically to the specimen. Hence the fixture freely allows the material to rotate interns reduces the torsion effect. The crack will propagate across the laminate. For SENB, Specimen was placed in between the two jaws of the testing machine the dial gauge of extensometer and vernier scale which as placed on the vertical column of the machine must be set to zero. The Precracked specimen was loaded at the center of the specimen with suitable loading device. There are five trails were conducted for each condition of the specimen. 


\section{Edge Notched Tension test (ENT)}

The ENT test specimens were prepared according to ASTM E1922 standard [13]. The crack has to be introduced by sawing a fine razor blade. The standard dimensions of the specimen are as shown below the Fig.1.

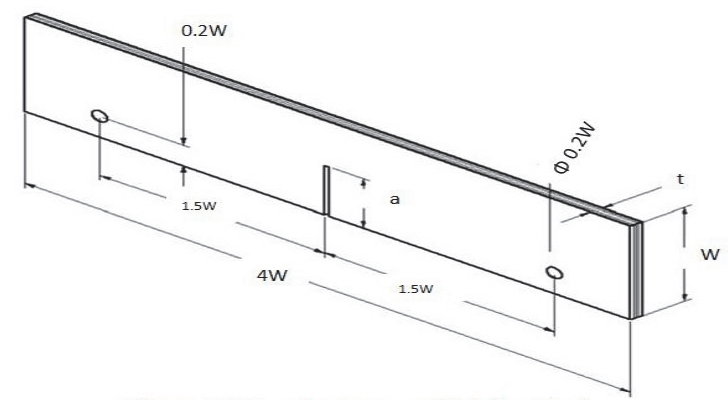

Figure 1: ENT specimen as per ASTM standard [13].

Single Edge Notched Bend (SENB)

Single edge notched bend specimen was prepared based upon the ASTM D5045 standard, and it involves the specimen has to be Precracked [14]. The standard specimen configuration of the specimen as shown in fig.2

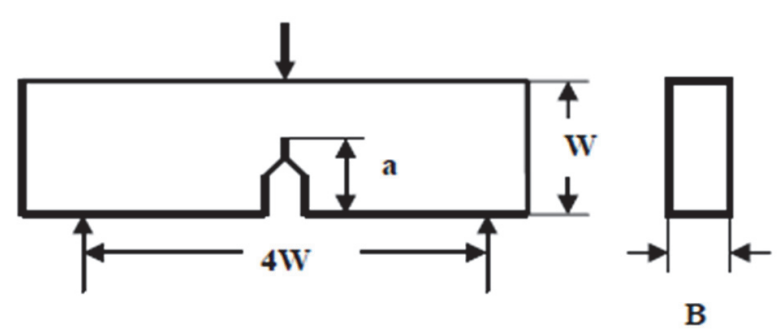

Figure 2: SENB specimen as per ASTM standard [14].

Experimental design for ENT and SENB test

\begin{tabular}{cccc}
\hline Trial & A & B & C \\
1 & 1 & 1 & 1 \\
2 & 1 & 2 & 2 \\
3 & 1 & 3 & 3 \\
4 & 2 & 1 & 3 \\
5 & 2 & 2 & 1 \\
6 & 2 & 3 & 2 \\
7 & 3 & 1 & 2 \\
8 & 3 & 2 & 3 \\
9 & 3 & 3 & 1 \\
\hline
\end{tabular}

Table 1: Experimental design using L9 OA [15] 


\begin{tabular}{ccccc}
\hline Code & Control factors & Level 1 & Level 2 & Level 3 \\
A & (a/w) ratio & 0.3 & 0.4 & 0.5 \\
B & Thickness (mm) & 7 & 10 & 12 \\
C & $\begin{array}{c}\text { Immersion time } \\
\text { (Days) }\end{array}$ & 7 & 14 & 21 \\
\hline
\end{tabular}

Table 2: Factors and levels considered

Taguchi's orthogonal array $(\mathrm{OA})$ table was prepared by choosing three control factors that could affect the load and facture toughness. Tab. 1 shows the parameters and the levels used in this experiment. The orthogonal array of L9 type was used and is represented in Tab. 2. L is Latin square and subscript 9 means the number of the experiment [15].

\section{Analysis Of Variance (ANOVA)}

Analysis of variance (ANOVA) is done on the MINITAB software. It gives a clear picture about the extent to which a particular process parameter affects the response. The main objective of this analysis is to estimate the relative contribution of each control factor to the overall response. The contributions are expressed in terms of percentage [16].

\section{Main Effect Plots}

The main effect plots are the mean response of each level factor connected by the line. When the line is in horizontal, there is no main effect present. Each factor for the level effects in the response same way the response means also same across the level. When the line is a small deflection from horizontal my significant effect on the response. Different levels of the factors may affect the response differently. Stepper the slope along the line shows the greater magnitude of the main effect [17].

\section{RESULTS AND DISCUSSION}

I $\mathrm{n}$ the present work, the effect of varying a/w, thickness and immersion time with a fixed percentage of polymer epoxy on the load carrying capacity and fracture have been identified experimentally. The configurations of the specimen for ENT and SENB tests were controlled by the ASTM E1922 and ASTM D5045 standards, respectively. Experimental results have been discussed throughout this section.

\section{Main effect plot for Edge Notched Tension (ENT) test}

The main effect plot of ENT test for load carrying capacity under sea water immersion is as presented in the Fig.3 (a). Failure with unstable crack growth is common problem accompanying with brittle polymer matrix composite [13]. Load carrying capacity decreases with increasing the ratio. This is because of the crack length increases, then the critical stresses are decreased inters reduces the load withstanding capacity [18]. Previously established in the literature the sea water formed in a closed cell of polymeric foams. The immersion time increases from 7 to 14 days, then the load carrying capacity decreases due to the significant moisture absorption, sea water degradation and plasticization of the matrix inter deboning of the fiber matrix interface. Again the load carrying capacity increase, when immersion time from 14 to 21 days is mainly due to the secondary mechanism of sea water provides the foam permeability which increases the $4 \%$ of weight gain [18]. There is no much deflects in the line of immersion time; this indicates that the sea water treatment does not the abundant cause of composite material.

Main effect plot for fracture toughness on ENT test under sea water immersion is as shown in Fig.4. Fracture toughness increases with increasing the a/w ratio because of the plastic zone size increases with increases crack length in the meantime energy required for growth of crack is high. As long as the material becomes thicker don't allow for the generation of the larger plastic zone, hence the fracture toughness decreases with increase in thickness of the composite [20]. The immersion time the seawater increases the fracture toughness decreases initially and again increases. It is observed that sea water treatment yields a higher value of fracture toughness [13]. 


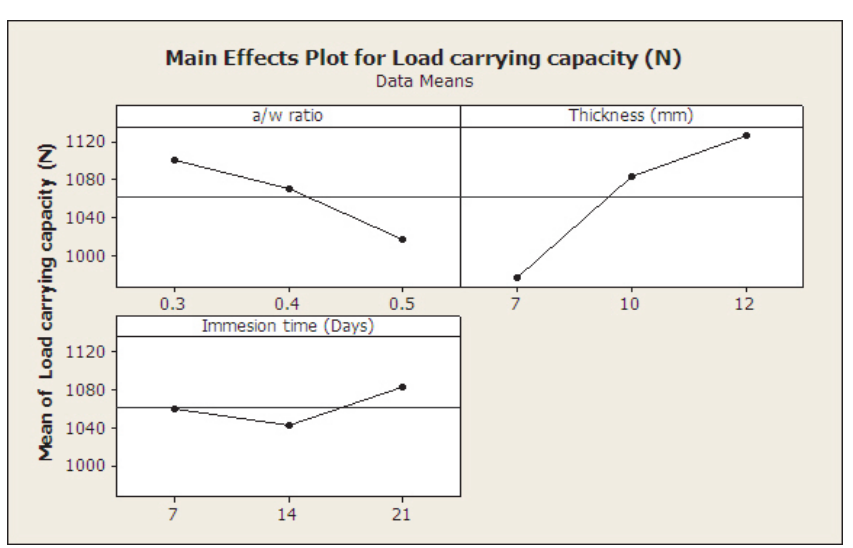

(a)

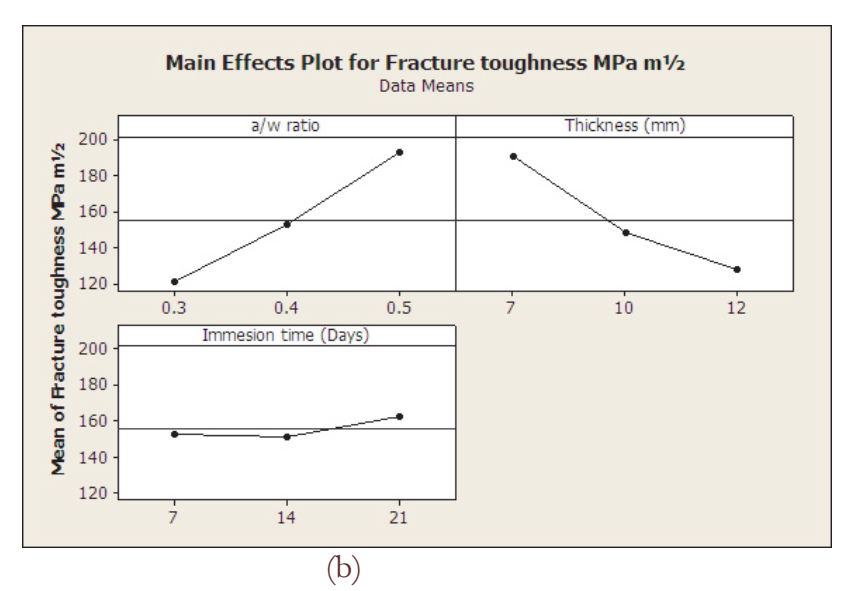

(b)

Figure 3: Main effect plot of (a) Load carrying capacity (b) Fracture toughness MPa m²1/2.

\section{Analysis of V ariance (ANOV A) for ENT test}

The percentage of contribution of each factor on load carrying capacity is clearly revealed in ANOVA as shown in Tab.3. The thickness is main factor influence on load carrying capacity is about $71.57 \%$. The percentage of contribution of a/w ratio is $21.39 \%$ and immersion time is $4.8 \%$. Here the sea water immersion is not a major influence on load carrying capacity. The error of $2.17 \%$ is due to the fabrication defects.

\begin{tabular}{ccccccc}
\hline Source & DF & SS & MS & F & P & $\begin{array}{c}\% \text { of } \\
\text { contribution }\end{array}$ \\
a/w ratio & 2 & 10688.9 & 5344.4 & 9.82 & 0.092 & 21.39 \\
$\begin{array}{c}\text { Thickness (mm) } \\
\text { Immersion Time }\end{array}$ & 2 & 35755.6 & 17877.8 & 32.84 & 0.030 & 71.57 \\
$\begin{array}{c}\text { (Days) } \\
\text { Error }\end{array}$ & 2 & 2422.2 & 1211.1 & 2.22 & 0.310 & 4.8 \\
Total & 1088.9 & 544.4 & & & 2.17 \\
\hline
\end{tabular}

Table 3: ANOVA for load carrying capacity

\begin{tabular}{ccccccc}
\hline Source & DF & SS & MS & F & P & $\begin{array}{c}\% \text { of } \\
\text { contribution }\end{array}$ \\
a/w ratio & 2 & 311.702 & 155.851 & 1.63 & 0.051 & 74.5 \\
Thickness (mm) & 2 & 78.439 & 39.220 & 4.69 & 0.176 & 18.74 \\
$\begin{array}{c}\text { Immersion Time } \\
\text { (Days) }\end{array}$ & 2 & 11.519 & 5.760 & 0.69 & 0.592 & 2.7 \\
Error & 2 & 16.728 & 8.364 & & & 3.9 \\
Total & 8 & 418.389 & & & & 100 \\
\hline
\end{tabular}

Table 4: ANOVA for Fracture toughness MPa m²/2.

ANOVA for the fracture toughness of JFRP under sea water environment is as shown in Tab. 4. The main influencing factor on the fracture toughness is the a/w ratio about $74.5 \%$. The thickness of the composite contributes about $18.74 \%$ to decrease the fracture toughness. And immersion time of $2.7 \%$ contributes to fracture toughness. It shows toughness alters very least by immersing the composite in sea water. The error of $3.9 \%$ is due to fabrication defects. 


\section{Main effect plot for Single Edge Notched Bend (SENB) test}

The main effect plot of load carrying capacity for SENB test under sea water environment is as shown in Fig.4 (a). The failure of the polymer composite by bending load causes the delamination. The delamination occurs over the edge region, predominantly due to the plane stress developed [19]. In the main effect, the plot shows that the load carrying capacity decreases with increase in a/w ratio. The load carrying capacity increases with an increase in thickness is due to the more surface area is exposed to the load. And also the load carrying capacity decreases initially and the increases small amount to an increase in immersion time. This is because of the structural degradation occurs within in laminates causes the rapture of blisters, and viscous acid is expelled with immersion [18]. Composite under wet condition showed an initial decrease in the load carrying capacity and again increases due to the plasticization of jute samples caused by moisture absorption. [21] Main effect plots of fracture toughness for SENB test under sea water environment are as shown in Fig.4 (b). Fracture toughness increases with increase in $\mathrm{a} / \mathrm{w}$ ratio. A large amount of energy is required for failure of the composite structure. As thickness increases the fracture toughness goes on decreases is due to the small quantity of water absorb over the voids and cracks, this damage the fiber exposed [22]. And immersions time also some little effect on fracture toughness which decreases initially and then increases. This is because of chemical degradation of fiber and matrix interface region [23].

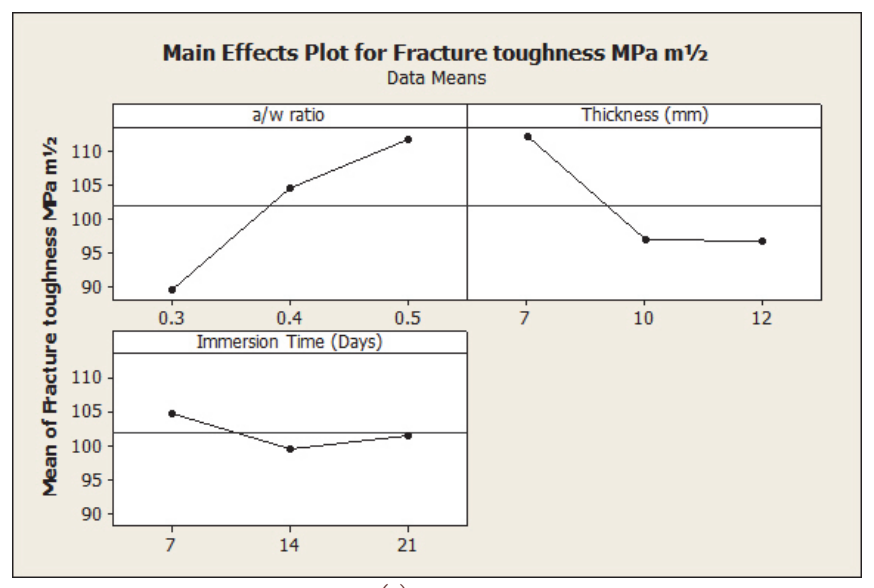

(a)

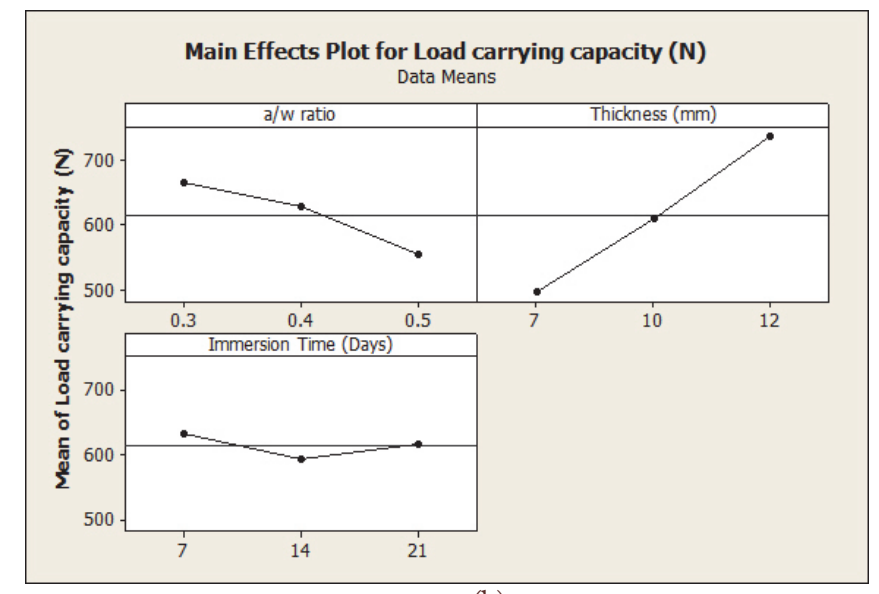

(b)

Figure 4: Main effect plot of (a) Load carrying capacity (b) Fracture toughness MPa m²/2.

\section{Analysis of Variance (ANOVA) for SENB test}

ANOVA for load carrying capacity of SENB test under sea water environment is as shown in Tab. 5. The major factor influencing on load carrying capacity is the thickness of $78.32 \%$. This is because of the larger surface area is exposed to the load. The a/w ratio is also contributing to load carrying capacity is about $17.09 \%$, but load carrying capacity decreases with increase in crack length. The immersion time is a very little contribution to just $2.19 \%$ of load carrying capacity. This shows that sea water treatment does not more effect on the reinforced composite. And the error of $2.4 \%$ is due to the fabrication defect.

\begin{tabular}{ccccccc}
\hline Source & DF & SS & MS & F & P & $\begin{array}{c}\% \text { of } \\
\text { contribution }\end{array}$ \\
A/W ratio & 2 & 18822 & 9411 & 7.00 & 0.125 & 17.04 \\
Thickness (mm) & 2 & 86489 & 43244 & 32.17 & 0.030 & 78.32 \\
$\begin{array}{c}\text { Immersion Time } \\
\text { (Days) }\end{array}$ & 2 & 2422 & 1211 & 0.90 & 0.526 & 2.19 \\
Error & 2 & 2689 & 1344 & & & 2.4 \\
Total & 8 & 110422 & & & & 100 \\
\hline
\end{tabular}

Table 5: ANOVA for load carrying capacity. 


\begin{tabular}{ccccccc}
\hline Source & DF & SS & MS & F & P & $\begin{array}{c}\text { \% of } \\
\text { contribution }\end{array}$ \\
A/W ratio & 2 & 761.58 & 380.79 & 14.7 & 0.063 & 57.34 \\
Thickness (mm) & 2 & 471.69 & 235.84 & 9.16 & 0.098 & 35.1 \\
$\begin{array}{c}\text { Immersion Time } \\
\text { (Days) }\end{array}$ & 2 & 43.26 & 21.63 & 0.84 & 0.544 & 3.25 \\
Error & 2 & 51.51 & 25.76 & & & 3.87 \\
Total & 8 & 1328.04 & & & & 100 \\
\hline
\end{tabular}

Table 6: ANOVA for Fracture toughness MPa m²/2.

The main influencing factor on the fracture toughness is the a/w ratio about $57.34 \%$ because of decrement in load withstanding capacity as shown in Tab. 6 . The thickness of the composite contributes about $35.1 \%$ to decrease the fracture toughness. This is due to the plastic zone size with increase in thickness [24]. And immersion time of $3.25 \%$ contributes to fracture toughness. It shows toughness alters very least by immersing the composite in sea water. The error of $3.87 \%$ is due to fabrication defects.

\section{EXPERIMENTAL VALIDATION BY LINEAR REGRESSIONS}

o obtain the relationship between the load carrying capacity / fracture toughness and different parameter such as a/w ratio, width and thickness in general and a/w ratio, thickness and immersion time for seawater treatment, mathematical equations were developed. The regression coefficients in a mathematical model are estimated experimental responding. To investigation of these models, experiments are executed by taking an arbitrary combination of factor and matched with the predicted values. These mathematical equations with different control were obtained using statistical software MINITAB [25].

\section{Mathematical Equations for ENT Test}

Load carrying capacity: $246-500 \mathrm{~A}+30.9 \mathrm{~T}+1.67 \mathrm{I}$

Fracture toughness: $31.5+72.1 \mathrm{~A}-1.12 \mathrm{~T}+0.133 \mathrm{I}$

\section{Mathematical Equations for SENB Test}

Load carrying capacity: 395- $550 \mathrm{~A}+47.2 \mathrm{~T}-1.19 \mathrm{I}$

Fracture toughness: $92.2+111 \mathrm{~A}-3.25 \mathrm{~T}-022 \mathrm{I}$

where,

$$
\begin{aligned}
& \mathrm{A}=\mathrm{a} / \mathrm{w} \text { ratio } \\
& \mathrm{T}=\text { Thickness }(\mathrm{mm}) \\
& \mathrm{I}=\text { Immersion time (days) }
\end{aligned}
$$

\section{EXPERIMENTAL VALIDATION OF ENT TEST}

$\mathrm{T}$

he comparison of load carrying capacity/fracture toughness from the mathematical model developed in the present work with values obtained experimentally. The Tab. 7 and Tab. 8 show the percentage of error from the experimental 
value corresponding predicted values for tests under sea water immersion. The difference in error for load carrying capacity is varies from 0.45 to $8.36 \%$. And the fracture toughness varies from 1.46 to $7.49 \%$.

\begin{tabular}{cccc}
\hline $\begin{array}{c}\text { Factor combination } \\
\text { (a/w, thickness mm, immersion } \\
\text { time) }\end{array}$ & $\begin{array}{c}\text { Experimental load } \\
(\mathrm{N})\end{array}$ & Predicted Load $(\mathrm{N})$ & \% Error \\
$0.3,7 \mathrm{~mm}, 7$ days & 351.106 & 323.99 & 8.36 \\
$0.4,10 \mathrm{~mm}, 14$ days & 376.66 & 378.38 & 0.45 \\
$0.5,12 \mathrm{~mm}, 21$ days & 375.55 & 401 & 6.77 \\
\hline
\end{tabular}

Table 7: Confirmation Test table for Load carrying capacity (N).

\begin{tabular}{cccc}
\hline $\begin{array}{c}\text { Factor combination } \\
(\mathrm{a} / \mathrm{w}, \text { thickness mm, immersion } \\
\text { time })\end{array}$ & $\begin{array}{c}\text { Experimental load } \\
(\mathrm{N})\end{array}$ & Predicted Load $(\mathrm{N})$ & \% Error \\
$0.3,7 \mathrm{~mm}, 7$ days & 49.59 & 46.22 & 7.29 \\
$0.4,10 \mathrm{~mm}, 14$ days & 51.75 & 51.00 & 1.46 \\
$0.5,12 \mathrm{~mm}, 21$ days & 52.98 & 59.90 & 7.39 \\
\hline
\end{tabular}

Table 8: Confirmation Test table for Fracture toughness MPa m²/2.

\section{EXPERIMENTAL VALIDATION OF SENB TEST}

$\mathrm{S}$

imilarly, Tab. 9 shows the SENB test for load carrying capacity under sea water immersion that difference in error varies from 3.33 to $8.27 \%$. And the fracture toughness varies from 0.6 to $1 \%$ is as shown in Tab.10.

\begin{tabular}{cccc}
\hline $\begin{array}{c}\text { Factor combination } \\
(\mathrm{a} / \mathrm{w} \text {, thickness mm, immersion } \\
\text { time) }\end{array}$ & $\begin{array}{c}\text { Experimental load } \\
(\mathrm{N})\end{array}$ & Predicted Load (N) & \% Error \\
$0.3,7 \mathrm{~mm}, 7$ days & 597.77 & 552.07 & 8.27 \\
$0.4,10 \mathrm{~mm}, 14$ days & 609.99 & 630.34 & 3.33 \\
$0.5,12 \mathrm{~mm}, 21$ days & 635.55 & 661.41 & 4.06 \\
\hline
\end{tabular}

Table 9: Confirmation Test table for Load carrying capacity $(\mathrm{N})$.

\begin{tabular}{cccc}
\hline $\begin{array}{c}\text { Factor combination } \\
\text { (a/w, thickness mm, immersion } \\
\text { time) }\end{array}$ & $\begin{array}{c}\text { Experimental load } \\
(\mathrm{N})\end{array}$ & Predicted Load $(\mathrm{N})$ & \% Error \\
$0.3,7 \mathrm{~mm}, 7$ days & 102.16 & 101.15 & 1 \\
$0.4,10 \mathrm{~mm}, 14$ days & 100.18 & 100.91 & 0.8 \\
$0.5,12 \mathrm{~mm}, 21$ days & 103.31 & 103.91 & 0.6 \\
\hline
\end{tabular}

Table 10: Confirmation Test table for Fracture toughness MPa m²². 


\section{RESPONSE SURFACE METHODOLOGY}

7 he influence of fracture parameters on a/w, thickness and immersion time can be analysed by using a 3-D response graph. These response surface graphs are drawn from varying two parameters over the load and fracture toughness [26].

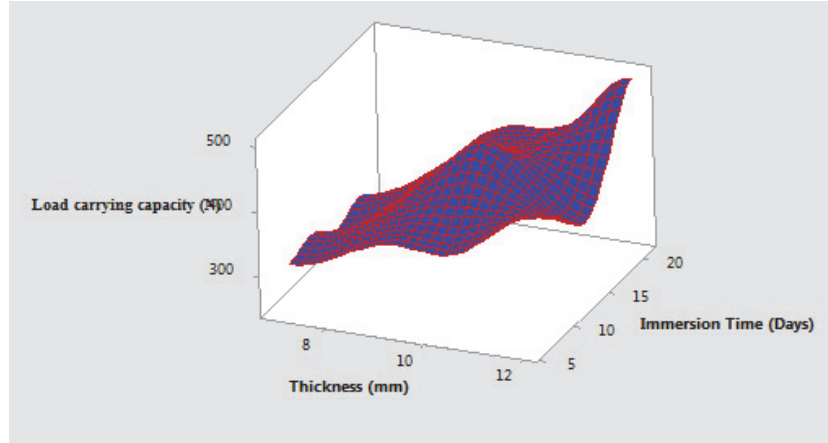

(a)

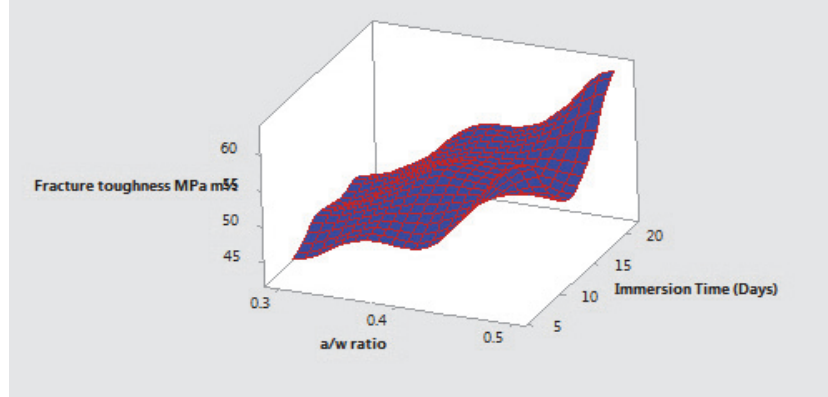

(c)

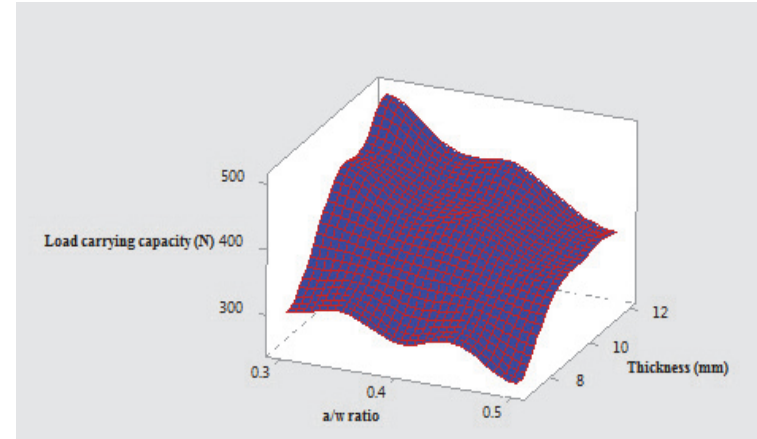

(b)

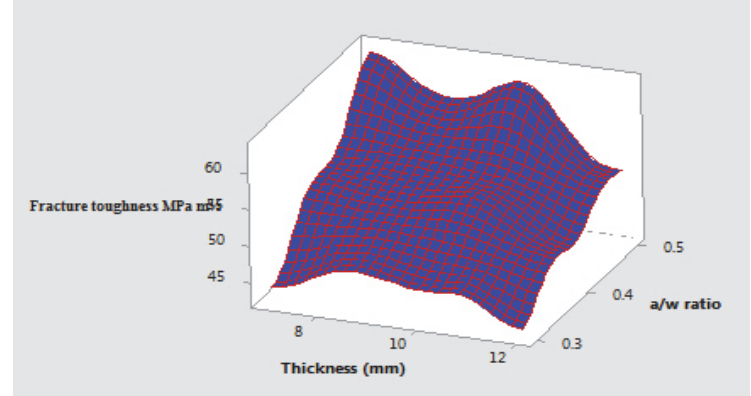

(d)

Figure 5: RSM graphs of different control factors V/S Load and Fracture toughness of ENT Test

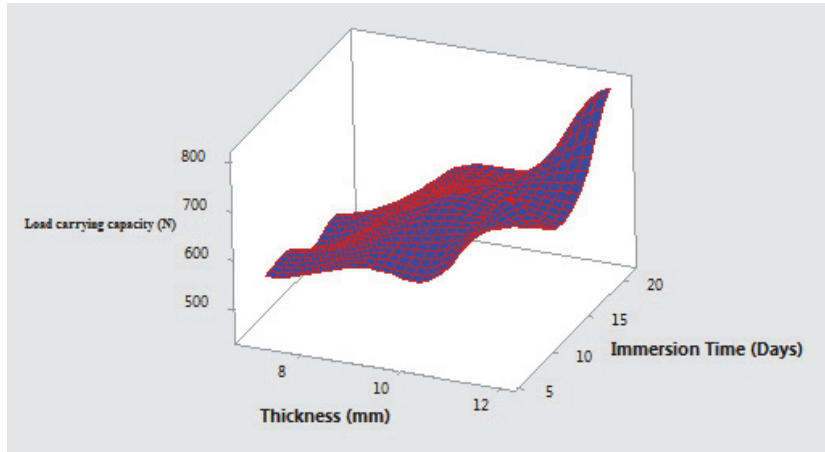

(a)

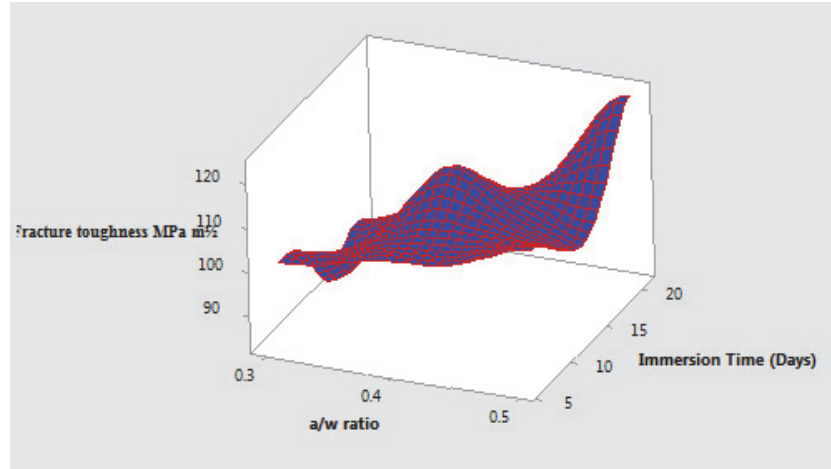

(c)

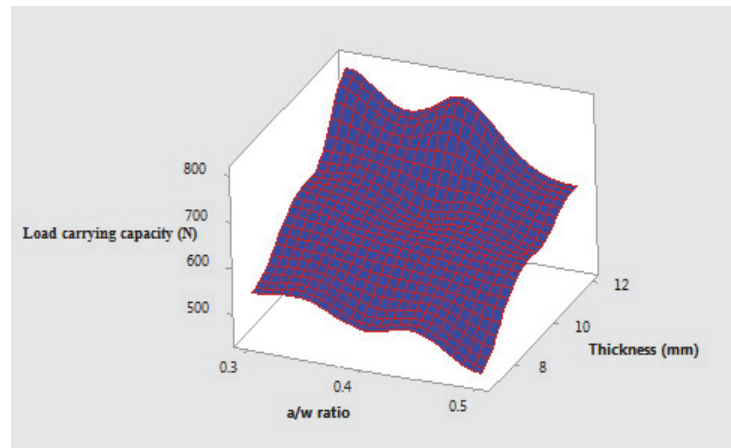

(b)

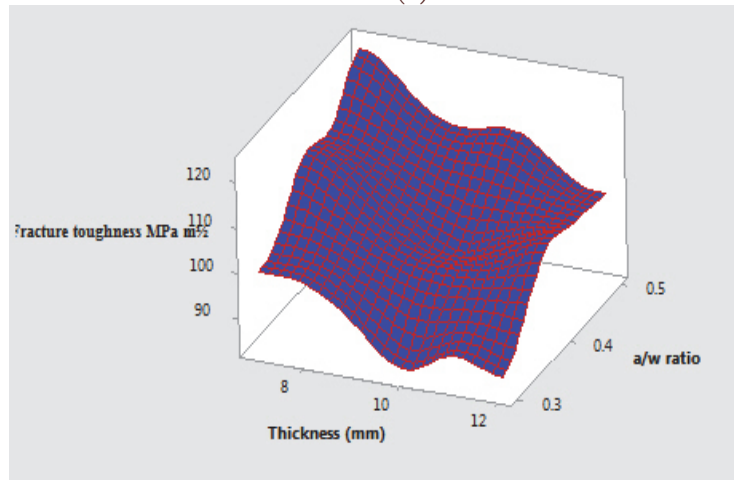

(d)

Figure 6: RSM graphs of different control factors V/S Load and Fracture toughness of SENB Test. 
Surface plot of Load carrying capacity/ Facture toughness vs. A/W ratio, Thickness and Immersion time is shown in Fig.5. \& Fig.6 for both ENT and SENB test. The figures clearly describe load carrying capacity increases on the thickness and decreases on a/w ratio. It also notices that the load initially decreased and then increases with immersion time in both ENT and SENB. The Fracture toughness decreases in thickness, increases on a/w ratio and initially decreases and then increases with immersion time in both ENT and SENB. The behaviour of the materials, which were treated with sea water environment, is noticed that, as the duration of immersion increases, fracture toughness also increased for all other control factors. It is observed that specimens with sea water treatment yielded a higher value of fracture toughness.

\section{CONCLUSIONS}

$\mathrm{F}$ ailure analysis of jute fiber reinforced composites has been made experimentally; the parameters such as load carrying capacity and fracture toughness have been identified for different control factors like a/w ratio and thickness. The effect of seawater immersion on this composite has evaluated. Taguchi method can be applied to experimental results using an L9 orthogonal array. Based on the results following conclusions were derived.

$>$ The load carrying capacity increases with thickness and decreases with a/w ratio, but The Facture toughness increases with $\mathrm{a} / \mathrm{w}$ and decreases with a thickness in both ENT and SENB respectively.

$>$ The percentage of contribution of the thickness of $71.57 \%$ and an a/w ratio of $21.39 \%$ of load carrying capacity, a/w ratio of $74.5 \%$ and Thickness of $35.1 \%$ on fracture toughness in ENT specimen.

$>$ The Composite specimen immersed in seawater has little influence on its $(4.8 \%, 2.19 \%)$ load carrying capacity and $(2.7 \%, 3.87 \%)$ fracture toughness on both ENT and SENB respectively.

$>$ The experimental validation with the predicted result shows the error of less than $10 \%$ is acceptable.

$>$ RSM graph shows the variation of fracture mechanics parameters with control factors.

$>$ These results highlight that the jute fibres may be considered as a possible alternative material could be used in the manufacturing of a boat.

\section{REFERENCES}

[1] Khan, R. A. et al. (2011). Comparative Studies of Mechanical and Interfacial Properties Between Jute Fiber/PVC and E-Glass Fiber/PVC Composites, Polymer-Plastics Technology and Engineering, 50(2), pp. 153-159.

DOI: $10.1080 / 03602559.2010 .531422$.

[2] Silva, R. V. et al. (2009) 'Curaua/Glass Hybrid Composite: The Effect of Water Aging on the Mechanical Properties', Journal of Reinforced Plastics and Composites, 28(15), pp. 1857-1868.

DOI: $10.1177 / 0731684408090373$.

[3] Akil, H. M. et al. (2009). Water absorption study on pultruded jute fibre reinforced unsaturated polyester composites, Composites Science and Technology 69(11-12), pp. 1942-1948.

DOI: 10.1016/j.compscitech.2009.04.014.

[4] Davidson, B. D., Soffa, M. A. and Kumar, M. (2008). Temperature and Moisture Effects in a Particulate Interlayered Composite: Mode I Data Reduction and Toughness, Journal of Reinforced Plastics and Composites, 28(17), pp. 2049_ 2068. DOI: $10.1177 / 0731684408090844$.

[5] Ni, Q.-Q. (2005). A Method to Evaluate Interfacial Fracture Energy on a Fibre/ Matrix Interface, Proceedings of the Institution of Mechanical Engineers, Part L: Journal of Materials: Design and Applications, 219(2), pp. 77-83. DOI: $10.1243 / 146442005 X 10274$.

[6] Brunner, A. J., Blackman, B. R. K. and Davies, P. (2008). A status report on delamination resistance testing of polymermatrix composites, Engineering Fracture Mechanics, 75(9), pp. 2779-2794.

DOI: 10.1016/j.engfracmech.2007.03.012.

[7] Kaman, M. O. (2011). Effect of fiber orientation on fracture toughness of laminated composite plates [0??/????]s, Engineering Fracture Mechanics. Elsevier Ltd, 78(13), pp. 2521-2534.

DOI: 10.1016/j.engfracmech.2011.06.005.

[8] Grau, D. L. (2006). Relation between Interfacial Fracture Toughness and Mode-mixity in Honeycomb Core Sandwich Composites, Journal of Sandwich Structures and Materials, 8(3), pp. 187-203. DOI: 10.1177/1099636206061774.

[9] Society, M. P.. From the SAGE Social Science Collections . All Rights Reserved, Social Science.

[10] Mikovic, J. and Velickovic, S. (2014). Application of Taguchi methods in testing tensile strength of polyethylene, 8th 
International Quality Conference, pp. 575-582.

[11] Vidal, C. et al..Application of Taguchi Method in the Optimization of Friction Stir Welding.

[12] Kondapalli, S. P., Chalamalasetti, S. R. and Damera, N. R. (2013). Application of Taguchi based Design of Experiments to Fusion Arc Weld Processes: A Review, International Journal of Technology and Management, 2(1), pp. 1-8.

[13] Arun, K. V., Basavarajappa, S. and Sherigara, B. S. (2010). Damage characterisation of glass/textile fabric polymer hybrid composites in sea water environment, Materials and Design. Elsevier Ltd, 31(2), pp. 930-939. DOI: 10.1016/j.matdes.2009.07.029.

[14] M.S. Sham Prasad, C.S. Venkatesha, T. J. (2011). Experimental Methods of Determining Fracture Toughness of Fiber Reinforced Polymer Composites under Various Loading Conditions, Journal of Minerals \& Materials Characterization \& Engineering, 10(13), pp. 1263-1275. DOI: 10.4236/jmmce.2011.1013099.

[15] Manjunath G. B, Bharath K. N, Vijaykumar, T. N. (2015). Optimization of Notch Parameter on Fracture Toughness of Natural Fiber Reinforced Composites Using Taguchi Method. Journal of Materials Science \& Surface Engineering, 3 (2), pp 244-248.

[16] Thirumavalavan, K., Karunamoorthy, L. and Padmanabhan, K. A. (2014). Optimization of Process Parameters Using Taguchi Technique in Severe Surface Mechanical Treatment of AA6061, 6(2), pp. 1026-1032.

[17] Jenarthanan, M. P. and Jeyapaul, R. (2013). Optimisation of machining parameters on milling of GFRP composites by desirability function analysis using Taguchi method, International Journal of Engineering, Science and Technology, 5(4), pp. 23-36.

[18] Du, Y., Yan, N. and Kortschot, M. T. (2014). The use of ramie fibers as reinforcements in composites, Biofiber Reinforcements in Composite Materials. DOI: 10.1533/9781782421276.1.104

[19] Directorate, M. and Base, W.A.F. (1997) 58(1), pp. 87-96.

[20] Low, I. M. et al. (2007). Mechanical and fracture properties of cellulose-fibre-reinforced epoxy laminates, Composites Part A: Applied Science and Manufacturing, 38(3), pp. 963-974. DOI: 10.1016/j.compositesa.2006.06.019.

[21] Deo, C. and Acharya, S. K. (2010). Effect of Moisture Absorption on Mechanical Properties of Chopped Natural Fiber Reinforced Epoxy Composite, Journal of Reinforced Plastics and Composites, 29(16), pp. 2513-2521. DOI: $10.1177 / 0731684409353352$

[22] Gope, P. C. and Rao, D. K. (2014). Fracture behaviour of epoxy biocomposite reinforced with short coconut fibres (Cocos nucifera) and walnut particles (Juglans regia L.), Journal of Thermoplastic Composite Materials, pp. 1-20. DOI: $10.1177 / 0892705714556835$.

[23] Siriruk, A., Penumadu, D. and Jack Weitsman, Y. (2009). Effect of sea environment on interfacial delamination behavior of polymeric sandwich structures, Composites Science and Technology, 69(6), pp. 821-828.

DOI: 10.1016/j.compscitech.2008.02.033.

[24] Mata, F. and Beamud, E. M. (2010). Response surface methodology ( RSM ) analysis approach to model experimental data of machining of plastic composites, XVIII Congreso Nacional de Ingeniería Mecánica.

[25] Manjunath, G. B. et al. (2017). ANOVA and Response Surface Methodology for the Optimization of Fracture Toughness parameters on Jute Fabric-Epoxy composites using SENB specimens, Materials Today: Proceedings. Elsevier Ltd, 4(10), pp. 11285-11291. DOI: 10.1016/j.matpr.2017.09.052.

[26] Govindaraju, R. et al. (2014). Optimization of Process Parameters for Fabrication of Wool Fiber-Reinforced Polypropylene Composites with Respect to Mechanical Properties, Journal of Engineered Fibers and Fabrics, 9(3), pp. 126-133. 